\title{
Peningkatan Produksi Melalui Penggunaan Varietas Unggul Baru pada Usahatani Bawang Merah
}

\section{Increased Production Through the Use of New High Yield Varieties in Shallot Cultivation}

\author{
Apresus Sinaga1, Abdul Rajab², Andi Faisal Suddin², Salim², dan Amisnaipa ${ }^{1}$ \\ ${ }^{1}$ Balai Pengkajian Teknologi Papua Barat \\ Jln. Trikora Anday, Kompleks Kementerian Pertanian, Anday, Manokwari Selatan \\ Manokwari, Papua Barat Kodepos 98315 \\ ${ }^{2}$ Balai Pengkajian Teknologi Pertanian Sulawesi Selatan \\ Jl. Perintis Kemerdekaan Km. 17,5, Sudiang PO Box 1234, Makassar 90242 \\ Email: apresusnaga@gmail.com
}

Diterima: 9 September 2020

Revisi: 8 Maret 2020

Disetujui: 30 Maret 2021

\begin{abstract}
ABSTRAK
Tujuan penelitian untuk mendapatkan informasi produktivitas tanaman bawang merah serta melihat respons petani dan hasil analisis kelayakan usahatani bawang merah. Penelitian dilaksanakan pada lahan petani di Desa Bonto Karaeng, Kecamatan Sinoa, Kabupaten Bantaeng, Provinsi Sulawesi Selatan pada bulan Januari-Desember 2019. Studi dilakukan untuk melihat perbedaan hasil bawang merah antara varietas Super Philips, Mentes, Trisula dan varietas lokal Bantaeng. Data dianalisis secara deskriptif dan respons petani didapatkan dengan wawancara menggunakan kuesioner. Untuk mengetahui tingkat kelayakan usahatani dilakukan analisis rasio penerimaan terhadap biaya R/C rasio (revenue cost ratio) dan analisis rasio keuntungan terhadap biaya $\mathrm{B} / \mathrm{C}$ rasio (benefit cost ratio). Selanjutnya dihitung tingkat titik impas produksi dan harga. Hasil penelitian menunjukkan bahwa rata-rata produksi bawang merah tertinggi varietas Super Philips sebesar 11,23 ton/ha sedangkan varietas lokal Bantaeng sebesar 5,20 ton/ha. Nilai rasio terhadap biaya pada semua tanaman bawang merah memperoleh nilai $R / C>1$. Nilai rasio keuntungan terhadap biaya dengan nilai $B / C>1$ diperoleh pada tanaman bawang merah varietas Super Philips, Mentes dan Trisula, sedangkan bawang merah varietas lokal Bantaeng menunjukkan nilai $\mathrm{B} / \mathrm{C}<1$. Usahatani bawang merah di lokasi penelitian memiliki daya saing yang cukup tinggi karena memiliki titik impas produksi (TIP) dan titik impas harga $(\mathrm{TIH})$ lebih rendah dari nilai harga dan nilai produksi bawang merah.

kata kunci : produksi, respons, analisis usahatani bawang merah
\end{abstract}

\section{ABSTRACT}

The research aimed to obtain information on each shallot variety's productivity, determine the farmers' response towards the new varieties, and conduct the feasibility analysis of shallot farming. The research was conducted on farmers' land in Bonto Karaeng Village, Sinoa District, Bantaeng Regency, South Sulawesi Province from January 2019 to December 2019. The treatment was conducted to see the differences in productivity among shallot varieties (Super Philips, Mentes, Trisula, and a local variety from Bantaeng Regency). The data were analyzed descriptively, and farmer responses were obtained through interview using questionnaires. To determine the feasibility of farming, an analysis of the revenue cost ratio $(R / C$ ratio) and the benefit-cost ratio $(B / C$ ratio) were carried out. Furthermore, the production break-even point and price break-even point are calculated. The results showed that the Super Philips variety had the highest average production (11.23 tons/ha) compared to the local Bantaeng variety at 5.20 tons/ha. The revenuecost ratio on all shallot plants obtained an $R / C$ value $>1$, and the value of benefit-cost ratio with $B / C>1$ value was obtained by Super Philips, Mentes, and Trisula varieties. In contrast, the local Bantaeng variety showed a value $B / C<1$. Shallot farming on the research location shows relatively high competitiveness because it has a production break-even point (TIP) and a price break-even point (TIH) lower than shallots' price and production value.

keywords: production, response, analysis of shallot farming 


\section{PENDAHULUAN}

Sektor pertanian memegang peranan yang penting dan strategis. Pertanian bawang merah memberikan kontribusi yang cukup tinggi terhadap perkembangan ekonomi wilayah, terutama di daerah sentra produksi, karena dapat menjadi sumber pendapatan serta menciptakan lapangan pekerjaan (Apurwanti, dkk., 2020).

Produksi bawang merah Sulawesi Selatan tahun 2019 sebesar 6,22 persen dari produksi bawang merah nasional (Badan Pusat Statistik dan Direktorat Jenderal Hortikultura, 2019). Produksi bawang merah di Desa Bonto Karaeng, Kecamatan Sinoa, Kabupaten Bantaeng masih di bawah produksi nasional sebesar 0,45 persen (Kementan, 2015).

Banyak faktor yang menyebabkan produktivitas bawang merah di Sulawesi Selatan masih rendah, salah satunya karena budidaya dilakukan dengan cara konvensional. Sudaryono, dkk. (2013) mengatakan, penggunaan benih secara turun temurun tanpa dilakukan pemurnian melalui seleksi massa dari populasi tanaman yang terbaik akan menurunkan kualitas dan produksi. Selain ditentukan oleh faktor genetik, tanaman harus mampu beradaptasi terhadap kondisi lingkungan tumbuhnya untuk mencapai pertumbuhan dan hasil yang optimal (Basundari dan Krisdianto, 2019). Penggunaan bibit unggul merupakan salah satu faktor yang menentukan keberhasilan usahatani bawang merah (Putrasamedja, 2011). Penggunaan varietas unggul merupakan salah satu teknologi inovatif yang andal untuk meningkatkan produktivitas, baik melalui peningkatan potensi atau daya hasil tanaman maupun toleransi ketahanannya terhadap cekaman biotik dan abiotik (Sembiring, 2007). Guswara dan Samaullah (2008) berpendapat bahwa varietas unggul baru adalah salah satu komponen teknologi yang andal dan murah karena petani hanya cukup mengganti varietas tanpa mengubah komponen lainnya. Varietas unggul baru memiliki kelebihan atau karakteristik yang menonjol seperti respons terhadap pemupukan, produksi tinggi, umur pendek, jumlah anakan banyak dan tahan terhadap hama penyakit (Nurhati, dkk., 2008)

Penelitian introduksi varietas unggul baru bawang merah harus dilakukan untuk mendapatkan informasi produksi yang spesifik lokasi serta melihat respons dan hasil analisis kelayakan usahatani bawang merah di Desa Bonto Karaeng, Kecamatan Sinoa, Kabupaten Bantaeng.

\section{METODOLOGI}

Pengkajian dilaksanakan di lahan kering seluas 0,2 ha di Desa Bonto Karaeng, Kecamatan Sinoa, Kabupaten Bantaeng, Sulawesi Selatan. Kabupaten Bantaeng memiliki ketinggian sekitar 500-1000 meter dari permukaan laut (mdpl), secara geografis terletak $\pm 120 \mathrm{~km}$ arah selatan Makassar, Ibukota Provinsi Sulawesi Selatan dengan posisi $5^{\circ} 21^{\prime} 13^{\prime \prime} 5^{\circ} 35^{\prime} 26^{\prime \prime}$ Lintang Selatan dan $119^{\circ} 51^{\prime} 42^{\prime \prime}-120^{\circ} 05^{\prime} 27^{\prime \prime}$ Bujur Timur. Iklim di daerah ini tergolong iklim tropis basah dengan curah hujan tahunan rata-rata setiap bulan 14 $\mathrm{mm}$. Penelitian dilaksanakan secara langsung di lahan petani pada Kelompok Tani Suka Maju, dengan menggunakan pendekatan partisipatif. Penelitian dilaksanakan pada bulan Januari sampai dengan Desember 2019.

Bahan yang digunakan dalam penelitian menggunakan benih varietas unggul baru yang berasal dari Balai Penelitian Tanaman Sayur Lembang dengan kelas benih sebar yaitu bawang varietas Mentes, Trisula dan Super Philips. Selain itu, digunakan pupuk kompos, urea, SP-36, $\mathrm{KCl}$ dan fungisida. Tanaman petani digunakan sebagai pembanding menanam bawang merah varietas lokal Bantaeng.

Pengolahantanah dilakukansecara sempurna pada kedalaman $\pm 20 \mathrm{~cm}$ menggunakan traktor. Tanah hasil olahan dibuat bedengan kemudian ditutup dengan mulsa plastik hitam perak. Benih ditanam setelah disimpan selama 2-3 bulan. Ukuran umbi sedang 3-4 gram/umbi, bernas, kulit umbi mengkilat dan tidak luka. Benih diberi perlakuan fungisida (b.a. mankozeb), Antracol 70 WP, Daconil 70 WP, sebanyak $100 \mathrm{~g}$ per $100 \mathrm{~kg}$.

Cara tanam dengan sistem tegel $(20 \times 20$ $\mathrm{cm})$. Jumlah bibit yang ditanam berjumlah 1 buah per lubang tanam. Bibit sebelum ditanam harus dipotong sebesar $1 / 4$ umbi agar tunas cepat tumbuh. Penyulaman dilakukan apabila tanaman mati atau pertumbuhan tidak normal, lama penyulaman 2 minggu setelah tanam (mst). 
Pemupukan diberikan dua kali, pemupukan pertama (pupuk dasar), terdiri dari pupuk organik (kompos) 5 ton/ha dan SP-36 dengan dosis $200 \mathrm{~kg} / \mathrm{ha}$, diaplikasikan pada 7 hari sebelum tanam. Pupuk susulan diberikan pada umur $10 \mathrm{hst}$ dan $30 \mathrm{hst}$. Jenis dan dosis pupuk yang diberikan adalah urea $100 \mathrm{~kg} / \mathrm{ha}, \mathrm{KCl} 100$ $\mathrm{kg} / \mathrm{ha}$, dan ZA $150 \mathrm{~kg} / \mathrm{ha}$. Pemberian pupuk dilakukan dengan cara menugal di sebelah kiri atau kanan tanaman dengan jarak $\pm 5 \mathrm{~cm}$ dari tanaman, kemudian lubang hasil tugalan ditutup kembali. Penyiraman menggunakan sprinkle atau dengan cara mengalirkan air ke dalam saluran drainase atau menggunakan gembor. Penyiangan dilakukan dua kali, yaitu sebelum pemupukan pertama dan sebelum pemupukan susulan ke dua. Pengendalian hama dan penyakit dilakukan menggunakan Regent 2 liter/ha, Decis 2 liter/ha dan Daconil 2 liter/ha sedangkan pengendalian gulma menggunakan Supremo 5 liter/ha dan Rumphas 5 liter/ha.

Parameter yang diamati meliputi komponen hasil umbi bawang per hektare yang dipanen setelah umur 85 hst. Data dianalisis secara deskriptif. Untukmelihat respons petanidilakukan wawancara dan pencatatan menggunakan kuesioner. Untuk mengetahui tingkat kelayakan usahatani dilakukan analisis $\mathrm{R} / \mathrm{C}$ rasio dan analisis Marginal B/C rasio (Swastika, 2004). Selanjutnya dilakukan pendekatan untuk menghitung tingkat titik impas (Break even point/BEP) produksi dan harga (Zakaria, 2005).

\section{HASIL DAN PEMBAHASAN}

\subsection{Produksi Bawang Merah}

Hasil penelitian menunjukkan bahwa produktivitas berbagai varietas bawang merah di Desa Bonto Karaeng dapat dilihat pada Gambar 1. Produksi keempat varietas bawang merah tertinggi adalah bawang merah varietas Super Philips dengan berat kering 11,23 ton/ha sedangkan varietas Mentes sebesar 9,38 ton/ ha, Trisula 8,92 ton/ha, dan produksi terendah varietas lokal Bantaeng 5,20 (Gambar. 1). Hasil penelitian Yaqin dan Azizah (2015) menunjukkan pemberian perlakuan varietas dan jarak tanam varietas Super Philip memperoleh hasil tertinggi dibandingkan varietas Bauji dan Batu ljo.

Produksi varietas unggul baru bawang merah Super Philips memperoleh hasil tertinggi sebesar 116,04 persen dibandingkan tanaman varietas lokal Bantaeng, sedangkan varietas Mentes 80,38 persen dan Trisula sebesar 71,54 persen terhadap varietas lokal Bantaeng (Gambar. 1). Tinggi dan rendahnya jumlah biji bawang merah dipengaruhi faktor genetik dan sedikit faktor lingkungan (Azmi, dkk., 2016).

\subsection{Respons Petani terhadap Desiminasi Bawang Merah}

Respons petani terhadap penerapan komponen teknologi produksi bawang merah diuraikan pada Tabel 1. Respons petani yang memilih komponen teknologi penggunaan varietas baru mendapatkan porsi tertinggi,

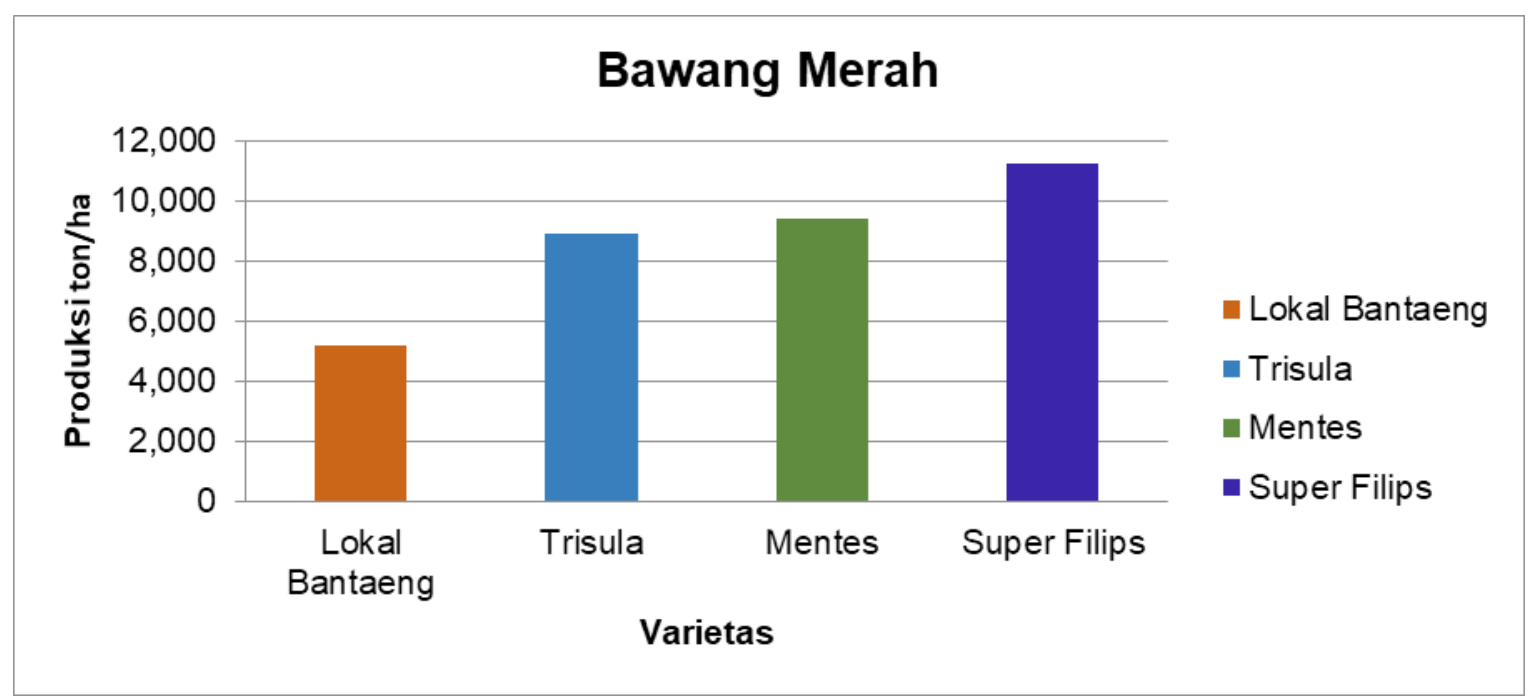

Gambar 1. Tingkat Produktivitas berbagai Varietas Bawang Merah di Desa Bonto Karaeng, Kecamatan Sinoa, Kabupaten Bantaeng, Sulawesi Selatan Tahun 2019 
Tabel 1. Respons Petani Terhadap Penerapan Komponen Teknologi pada Diseminasi Peningkatan Produksi Budidaya Bawang Merah di Desa Bonto Karaeng, Kecamatan Sinoa, Kabupaten Bantaeng, Tahun 2019.

\begin{tabular}{|c|c|c|c|c|c|}
\hline \multirow{2}{*}{ No } & \multirow{2}{*}{$\begin{array}{l}\text { Komponen } \\
\text { Teknologi }\end{array}$} & \multicolumn{3}{|c|}{ Prosentase Respons Petani $(\mathrm{N}=10)$} & \multirow{2}{*}{ Alasan } \\
\hline & & Menerima & Ragu-Ragu & Menolak & \\
\hline 1. & Varietas & 80 & 20 & 0 & $\begin{array}{l}\text { - Tahan cekaman iklim dan } \\
\text { gangguan Hama/penyakit } \\
\text { - Daya tumbuh benih } 95 \%\end{array}$ \\
\hline 2 & $\begin{array}{l}\text { Perlakuan } \\
\text { Benih }\end{array}$ & 70 & 20 & 10 & $\begin{array}{l}\text { - Bawang merah rentan terhadap } \\
\text { penyakit } \\
\text { - Mudah dilakukan }\end{array}$ \\
\hline 3 & $\begin{array}{l}\text { Pemupukan } \\
\text { Dasar }\end{array}$ & 30 & 30 & 40 & $\begin{array}{l}\text { - Gulma semakin banyak } \\
\text { - Biaya dan tenaga }\end{array}$ \\
\hline 4 & $\begin{array}{l}\text { Jarak tanam } \\
20 \mathrm{~cm} \times 20 \mathrm{~cm}\end{array}$ & 70 & 30 & 0 & $\begin{array}{l}\text { - Kebutuhan benih bertambah } \\
\text { - Jarak tanam teratur } \\
\text { - pemeliharaan mudah } \\
\text { - Penampilan menarik/rapi }\end{array}$ \\
\hline 5 & $\begin{array}{l}\text { Pemupukan } \\
\text { - Dosis } \\
\text { - Jenis } \\
\text { - Cara }\end{array}$ & $\begin{array}{l}30 \\
30 \\
30\end{array}$ & $\begin{array}{l}60 \\
50 \\
40\end{array}$ & $\begin{array}{l}10 \\
20 \\
30\end{array}$ & $\begin{array}{l}\text { - Repot dan butuh waktu dan } \\
\text { tenaga } \\
\text { - Sulit didapat di pasaran }\end{array}$ \\
\hline 6 & $\begin{array}{l}\text { Pengendalian } \\
\text { hama/ penyakit } \\
\text { berdasarkan } \\
\text { konsep PHT }\end{array}$ & 50 & 50 & 0 & $\begin{array}{l}\text { - Butuh waktu untuk melakukan } \\
\text { monitoring hama } \\
\text { - Khawatir tanaman gagal }\end{array}$ \\
\hline 7 & Penyimpanan & 60 & 20 & 20 & $\begin{array}{l}\text { - Butuh tempat khusus yang } \\
\text { berkualitas bagus }\end{array}$ \\
\hline
\end{tabular}

yaitu sebesar 80 persen, sedangkan petani yang masih ragu 20 persen. Respons petani ragu menerima bawang merah varietas Trisula karena varietas tersebut baru dikenal, padahal varietas Trisula mempunyai produksi yang tinggi dan tahan terhadap cekaman iklim yang ekstrem (kekeringan), hama/penyakit, serta mempunyai jumlah umbi sebanyak 6-12 umbi per pohon. Besaran respons petani terhadap perlakuan benih dan jarak tanam sebesar 70 persen, karena petani sudah melaksanakan dan memahami bahwa bawang merah rentan terhadap penyakit sehingga dengan jarak tanam teratur membuat pemeliharaan, pengendalian, gulma, hama dan penyakit bawang merah mudah dilakukan. Susanti dan Malik (2019) mengatakan pengetahuan dan respons terhadap komponen teknologi penanaman menurut petani mudah dipahami karena telah biasa dilakukan pada usahatani bawang merah yang dibudidayakan.

Respons petani terhadap perlakuan komponen teknologi pemupukan memperoleh hasil yang terendah, baik teknologi pemupukan dasar maupun pemupukan susulan. Petani yang menerima komponen teknologi pemupukan hanya sebesar 30 persen, sedangkan 30 persen masih ragu-ragu dan 40 persen menolak. Petani yang masih ragu terhadap teknologi pemberian pupuk dasar karena pemberian pupuk dasar menyebabkan pertumbuhan gulma disekitar tanaman bawang merah menjadi cepat. Respons petani terhadap komponen teknologi pemupukkan berdasarkan dosis, jenis dan cara pemupukkan yang menerima rata-rata 30 persen, ragu-ragu 50 persen sedangkan yang menolak sebesar 20 persen. Respons petani terhadap komponen teknologi pengendalian hama dan penyakit berdasarkan pengendalian hama terpadu (PHT), petani yang merespons teknologi 50 persen dan yang masih ragu terhadap teknologi PHT 50 persen. Respons petani terhadap teknologi penyimpanan benih bawang merah yang menerima 60 persen sedangkan yang masih ragu dan menolak 20 persen. 
Peranan sumber teknologi masih diperlukan khususnya dalam mengomunikasikan dalam bentuk kajian-kajian yang akan memberikan gambaran respons pengguna terhadap teknologi. Agar dapat diterima pengguna atau petani, perlu diperhatikan ketersediaan teknologi dan kemudahan untuk diaplikasikan di lapangan (Kiloes, dkk., 2020).

\subsection{Pendapatan Usahatani Bawang Merah}

Pendapatan bawang merah merupakan selisih antara penerimaan dengan total biaya yang dikeluarkan selama satu musim tanam, sedangkan keuntungan diperoleh dari selisih antara penerimaan dengan total biaya yang dikeluarkan selama satu musim tanam. Menanam dengan menerapkan pengelolaan tanaman terpadu pada usahatani bawang merah lebih menguntungkan dibandingkan menanam dengan cara petani.

Keuntungan yang diperoleh petani yang menanam varietas Super Philips sebesar Rp86.458.000,00/ha (192 persen), varietas
Mentes sebesar Rp64.210.000,00/ha (117 persen), dan varietas Trisula sebesar Rp58.690.000,00/ ha (98 persen) terhadap bawang merah varietas lokal Bantaeng yang ditanam dengan cara petani. Tabel 2, menunjukkan nilai rasio terhadap biaya pada semua tanaman bawang merah yang diteliti memperoleh nilai $\mathrm{R} / \mathrm{C}>1$ dan nilai rasio keuntungan terhadap biaya yang nilai $\mathrm{B} / \mathrm{C}>1$ diperoleh pada tanaman bawang merah varietas Super Philips, Mentes dan Trisula, sedangkan bawang merah varietas lokal Bantaeng menunjukkan nilai $\mathrm{B} / \mathrm{C}<1$.

Usahatani bawang merah varietas unggul baru Super Philips, Mentes dan Trisula secara finansial dan manfaat ekonominya sudah layak, sedangkan bawang merah varietas lokal Bantaeng yang ditanam dengan cara petani secara finansial layak tetapi manfaat secara ekonomi relatif masih rendah sehingga diperlukan langkah-langkah yang efektif untuk mendorong peningkatan produktivitas bawang merah cara petani tersebut ke arah produktivitas yang optimal dengan cara mengadopsi

Tabel 2. Analisis Usahatani Bawang Merah Irigasi di Desa Bonto Karaeng, Kecamatan Sinoa, Kabupaten Bantaeng, Sulawesi Selatan, Tahun 2019.

\begin{tabular}{|c|c|c|c|c|c|c|c|c|}
\hline \multirow{3}{*}{ Komponen Biaya } & \multicolumn{8}{|c|}{ Varietas Bawang Merah } \\
\hline & \multicolumn{2}{|c|}{ Super Philips } & \multicolumn{2}{|c|}{ Mentes } & \multicolumn{2}{|c|}{ Trisula } & \multicolumn{2}{|c|}{$\begin{array}{l}\text { Lokal Bantaeng } \\
\text { (cara petani) }\end{array}$} \\
\hline & $\begin{array}{l}\text { Nilai } \\
\text { (Rp } \\
\text { juta) }\end{array}$ & $\begin{array}{c}\text { Kontri } \\
\text { busi } \\
(\%)\end{array}$ & $\begin{array}{c}\text { Nilai } \\
\text { (Rp } \\
\text { juta) }\end{array}$ & $\begin{array}{c}\text { Kontri } \\
\text { busi } \\
(\%)\end{array}$ & $\begin{array}{c}\text { Nilai } \\
\text { (Rp } \\
\text { juta) }\end{array}$ & $\begin{array}{c}\text { Kontri } \\
\text { busi } \\
(\%)\end{array}$ & $\begin{array}{l}\text { Nilai } \\
\text { (Rp } \\
\text { juta) }\end{array}$ & $\begin{array}{c}\text { Kontri } \\
\text { busi } \\
(\%)\end{array}$ \\
\hline \multicolumn{9}{|l|}{ Biaya produksi } \\
\hline 1. Tenaga kerja & 5,55 & 11,48 & 5,55 & 11,48 & 5,55 & 11,48 & 0,00 & 0,00 \\
\hline Sub total $(A)$ & 5,55 & 11,48 & 5,55 & 11,48 & 5,55 & 11,48 & 0,00 & 0,00 \\
\hline \multicolumn{9}{|l|}{ Sarana produksi } \\
\hline 1. Benih & 35,00 & 72,39 & 35,00 & 72,39 & 35,00 & 35,00 & 30,00 & 91,60 \\
\hline \multicolumn{9}{|l|}{ 2. Pupuk } \\
\hline Pupuk Kandang & 5,00 & 10,34 & 5,00 & 10,34 & 5,00 & 10,34 & 0,00 & 0,00 \\
\hline Pupuk Anorganik & 1,50 & 3,10 & 1,50 & 3,10 & 1,50 & 3,10 & 1,25 & 3,82 \\
\hline 3. Pestisida/herbisida & 1,30 & 2,69 & 1,30 & 2,69 & 1,30 & 2,69 & 1,50 & 4,58 \\
\hline Sub total $(B)$ & 42,80 & 88,52 & 42,80 & 88,52 & 42,80 & 88,52 & 32,75 & 100,00 \\
\hline Total pengeluaran $(A+B)$ & 48,35 & 100,00 & 48,35 & 100,00 & 48,35 & 100,00 & 32,75 & 100,00 \\
\hline \multicolumn{9}{|l|}{ Hasil usahatani } \\
\hline 1. Penerimaan & 134,81 & & 112,56 & & 107,04 & & 62,40 & \\
\hline 2. Keuntungan & 86,46 & & 64,21 & & 58,69 & & 29,65 & \\
\hline 3. $\mathrm{R} / \mathrm{C}$ & 2,79 & & 2,33 & & 2,21 & & 1,91 & \\
\hline 4. $B / C$ & 1,79 & & 1,33 & & 1,21 & & 0,91 & \\
\hline
\end{tabular}


Tabel 3. Analisis Kelayakan dan Tingkat Titik Impas Usahatani Bawang merah di Desa Bonto Karaeng, Kecamatan Sinoa, Kabupaten Bantaeng, Sulawesi Selatan, Tahun 2019.

\begin{tabular}{lrrrr}
\hline & \multicolumn{3}{c}{ Kelayakan dan Tingkat BEP } \\
\cline { 2 - 5 } \multicolumn{1}{c}{ Uraian } & \multicolumn{1}{c}{$\begin{array}{c}\text { Super } \\
\text { Philips }\end{array}$} & \multicolumn{1}{c}{ Mentes } & Trisula & $\begin{array}{c}\text { Lokal } \\
\text { Bantaeng } \\
\text { (Cara Petani) }\end{array}$ \\
\hline Produksi bawang merah (kg/ha) & 11.234 & 9.380 & 8.920 & 5.200 \\
Harga (Rp/kg) & 12.000 & 12.000 & 12.000 & 12.000 \\
Penerimaan (Rp juta) & 134.808 .000 & 112.560 .000 & 107.040 .000 & 62.400 .000 \\
Total Biaya (Rp juta) & 48.350 .000 & 48.350 .000 & 48.350 .000 & 32.750 .000 \\
Keuntungan (Rp juta) & 86.458 .000 & 64.210 .000 & 58.690 .000 & 29.650 .000 \\
TIP (kg/ha) & 4.029 & 4.029 & 4.029 & 2.729 \\
TIH (Rp/kg) & 4.304 & 5.155 & 5.420 & 6.298 \\
\hline
\end{tabular}

komponen teknologi pengelolaan tanaman secara terpadu. Rusdi dan Asaad (2016) mengatakan agar produksi bawang merah dapat dicapai secara optimal maka diperlukan pengetahuan ukuran benih umbi minimal yang dapat berproduksi tinggi dan ukuran umbi yang diterima pasar untuk dapat diestimasi efisiensi biaya usahatani bawang merah, sehingga memberikan keuntungan lebih tinggi bagi petani. Pemanfaatan inovasi sebagai hasil dari kegiatan penyuluhan, berpeluang tinggi untuk meningkatkan produksi dan pendapatan petani (Mardiharini, dkk., 2019).

\subsection{Kelayakan Usahatani Bawang Merah}

Hasil analisis usahatani bawang merah menunjukkan titik impas produktivitas varietas Super Philips sebesar $4.029 \mathrm{~kg} / \mathrm{ha}(178,82$ persen) dari nilai aktual $11.234 \mathrm{~kg} / \mathrm{ha}$, varietas Mentes mempunyai nilai sebesar $4.029 \mathrm{~kg} / \mathrm{ha}$ (132,80 persen) dari nilai aktual $9.380 \mathrm{~kg} / \mathrm{ha}$. TIP bawang merah varietas Trisula mempunyai nilai sebesar $4.029 \mathrm{~kg} / \mathrm{ha}(121,39$ persen) dari nilai aktual $8.920 \mathrm{~kg} / \mathrm{ha}$ sedangkan bawang merah varietas lokal Bantaeng mempunyai nilai TIP sebesar $2.729 \mathrm{~kg} / \mathrm{ha}(90,53$ persen) dari nilai aktual $5.200 \mathrm{~kg} / \mathrm{ha}$ (Tabel.3).

Nilai titik impas harga dari keempat varietas bawang merah menunjukan bertoleransi terhadap nilai harga aktualnya. Bawang merah varietas Super Philips memiliki toleransi terhadap harga aktual sebesar 64,13 persen, varietas Mentes sebesar 57,05 persen, dan varietas Trisula sebesar 54,83 persen sedangkan varietas lokal Bantaeng sebesar 47,52 terhadap harga aktual (Tabel 3).

Hasil penelitian usahatani bawang merah di Desa Bonto Karaeng yang mengintroduksikan bawang merah varietas unggul dengan penerapan teknologi tanaman terpadu lebih efisien dibandingkan usahatani bawang merah dengan cara petani. Usahatani bawang merah di lokasi penelitian menunjukkan daya saing yang cukup tinggi karena memiliki TIP dan $\mathrm{TIH}$ lebih rendah dari nilai aktual harga dan nilai aktual produksi (Tabel. 3). Sesuai dengan hasil penelitian Giyanti (2019) menyebutkan, petani yang mengusahakan usahatani berada dalam keadaan yang menguntungkan apabila titik impas harga dan titik impas produksi lebih rendah dari nilai aktual harga dan produksi.

\section{KESIMPULAN}

Daya adaptasi ketiga bawang merah varietas unggul baru varietas Super Philips, Mentes dan Trisula sangat tinggi dibandingkan varietas lokal Bantaeng. Secara finansial dan manfaat ekonomi tanaman bawang merah varietas Super Philips, Mentes dan Trisula sudah layak dikembangkan dan menguntungkan dengan tingkat $R / C>1$ dan $B / C>1$.

Respons petani menerima tertinggi terhadap komponen teknologi penggunaan varietas unggul baru dan perlakuan jarak tanam yang teratur. Usahatani bawang merah irigasi memiliki daya saing yang cukup tinggi sebab titik impas produksi dan titik impas harga lebih rendah dari nilai harga dan produksi. 


\section{UCAPAN TERIMA KASIH}

Penulis sampaikan ucapan terima kasih sebesarbesarnya kepada Kepala dan Staff BPTP Balitbangtan Sulawesi Selatan dan semua rekan PPL dan petani yang telah membantu penelitian.

\section{DAFTAR PUSTAKA}

Apurwanti, E. D., E. S. Rahayu, dan H. Irianto. 2020. Analisis Efisiensi Rantai Pasok Bawang Merah Di Kabupaten Bantul. Jurnal Pangan. Vol.29(1): 1-12. DOI: https://doi.org/10.33964/jp.v29i1.463

Azmi, C., I. M. Hidayat, dan G. Wiguna. 2016. Pengaruh Varietas dan Ukuran Umbi terhadap Produktivitas Bawang Merah. Jurnal Hortikultura. Vol.21(3): 206.

Basundari, F.R.A. dan A.Y. Krisdianto. 2019. Pengaruh Dosis Pupuk dan Jarak Tanam pada Budidaya Bawang Merah di Luar Musim Tanam di Desa Klaigit Kabupaten Sorong. Jurnal Pangan. Vol.29(1): 13-24. DOI: https://doi. org/10.33964/jp.v29i1.467.

BPS. 2019. Sulawesi Selatan Dalam Angka.1-566.

Badan Pusat Statistik dan Direktorat Jenderal Hortikultura. 2019. Produksi Bawang Merah Menurut Provinsi, Tahun 2015-2019.

Giyanti. 2019. Analisis Pendapatan dan Titik Impas Usahatani Bawang merah (Oryza Sativa.L) di Desa Citra Manunggal Jaya Kecamatan Kaliorang Kabupaten Kutai Timur. Epp. Vol.9 (1): 1-8.

Guswara, A. dan M. Y. Samaullah. 2008. Penampilan beberapa varietas unggul baru pada sistem pengelolaan tanaman dan sumberdaya terpadu di lahan sawah irigasi. Prosiding BB Padi. 629636.

Kementan. 2019. Rencana Strategi Kementerian Pertanian Tahun 2015-2019:1-364.

Kiloes, A. M., P. Puspitasari, dan Y. Sastro. 2020. Persepsi Petani Partisipatif Terhadap Atribut Inovasi Dan Potensi Adopsi Paket Teknologi Produksi Lipat Ganda Bawang Merah. Jurnal Pengkajian dan Pengembangan Teknologi Pertanian. Vol.22(1):1.

Mardiharini, M., Sumardjo, P. Tjitropranoto, dan D. Sadono. 2019. Perbedaan Kapasitas dan Kapabilitas Petani Padi dan Bawang Merah dalam Upaya Meningkatkan Produktivitas Usahatani. Jurnal Pengkajian dan Pengembangan Teknologi Pertanian. Vol.22(3): 327-341.

Nurhati, I., S. Ramdhaniati, dan N. Zuraida. (2008). Peranan dan dominasi varietas unggul baru dalam peningkatan produksi padi di Jawa Barat. Buletin Plasma Nutfah. Vol.14(1): 8-13.

Putrasamedja, S. 2011. Uji pendahuluan klon-klon hasil silangan bawang merah pada musim penghujan di lembang. Agrin. Vol.15(1): 27-35.

Rusdi dan M. Asaad. 2016. Uji Adaptasi Empat Varietas Bawang Merah di Kabupaten Kolaka Timur, Sulawesi Tenggara. Jurnal Pengkajian dan Pengembangan Teknologi Pertanian. Vol.19(3): 243-252.

Sembiring, H. 2007. Kebijakan Penelitian dan Rangkuman Hasil Penelitian BB Padi dalam Mendukung Peningkatan Produksi Beras Nasional. Apresiasi Hasil Penelitian. BB Padi. 39-59.

Sudaryono, T., K. B. Andri, dan S. Purnomo. 2013. Pengembangan Varietas Bawang Merah Potensial dari Jawa Timur. Inovasi Hortikultura Pengungkit Peningkatan Pendapatan Rakyat. 5-20.

Susanti, E.Y. dan R. J. Malik. 2019. Efektivitas Metode Temu Teknis terhadap Perubahan Pengetahuan dan Respon Petani terhadap Budidaya Bawang Merah di Kabupaten Serang, Banten. Prosiding Temu Teknis Jabatan Fungsional Non Peneliti. Malang 17-19 Juli.

Swastika, D.K.S. 2004. Beberapa teknik analisis dalam penelitian dan pengkajian teknologi pertanian. Jurnal Pengkajian dan Pengembangan Teknologi Pertanian. Vol. 7(1): 90-103.

Yaqin, N.A., N. Azizah. dan R. Soelistyono. 2015. Peramalan Waktu Panen Tiga Varietas Tanaman Bawang Merah (Allium ascalonicum. L) Berbasis Heat Unit Pada Berbagai Kerapatan Tanaman. Jurnal Produksi Tanaman. Vol.3(5): 433-411.

Zakaria, A. K. 2010. Tingkat Adopsi Teknologi Budi Daya Kedelai pada Lahan Sawah Irigasi di Pasuruan, Jawa Timur. Jurnal IImu Pertanian dan Peternakan. Vol.29(3): 180-185. 


\section{BIODATA PENULIS:}

Apresus Sinaga dilahirkan di Kabupaten Labuhanbatu, tanggal 04 November 1979. Penulis menyelesaikan pendidikan sarjana di Program Studi Agronomi, Fakultas Pertanian, Universitas Papua pada tahun 2005. Magister Sains pada Program Studi Agronomi, Fakultas Pertanian, Universitas Gadjah Mada tahun 2016.

Abdul Rajab dilahirkan di Kabupaten Bulukuma, tanggal 15 Mei 1967. Penulis menyelesaikan pendidikan sarjana di Program Studi Budidaya Pertanian, Sekolah Tinggi IImu Pertanian (STIP) Al Gazhali pada tahun 1993. Magister Sains pada Program Studi Sistem-Sistem Pertanian, Fakultas Pertanian, Universitas Hasanuddin tahun 2012.

Andi Faisal Suddin dilahirkan di Kabupaten Bone, tanggal 21 Agustus 1976. Penulis menyelesaikan pendidikan sarjana di Program Studi Agronomi, Fakultas Pertanian dan Kehutanan, Universitas Hasanuddin pada tahun 2001. Magister Sains pada Program Studi Agribisnis, Fakultas Pertanian, Universitas Hasanuddin tahun 2009.

Salim dilahirkan di Bulucenrana Kabupaten Sidenreng Rappang (SIDRAP), tanggal 14 Februari 1979. Penulis menyelesaikan pendidikan sarjana di Program Studi IImu Hama dan Penyakit Tumbuhan, Fakultas Pertanian dan Kehutanan, Universitas Hasanuddin pada tahun 2004. Magister Sains pada Program Studi IImu Hama dan Penyakit Tumbuhan, Fakultas Pertanian, Universitas Hasanuddin tahun 2019.

Amisnaipa, dilahirkan di Ujung Pandang, tanggal 23 Maret 1973. Penulis menyelesaikan pendidikan sarjana pada program studi Agronomi Fakultas Pertanian (Faperta) UNCEN Manokwari 1992. Magister Sains pada program studi Ekofisiologi Pertanian Fakultas Pertanian IPB tahun 2007 dan menyelesaikan program Doktoral pada Fakultas Pertanian Institute Pertanian Bogor tahun 2015. 